\title{
Design of Household Photovoltaic Grid-connected Inverter Based on STC
}

\author{
Zhong-mei Xi \\ College of Mechanical \& Electronic Engineering \\ Shandong Agricultural University \\ Shandong provincial Key Laboratory of Horticultural \\ Machineries and Equipments \\ Tai'an, China \\ xizhongmei@126.com
}

\author{
Yang Li \\ College of Mechanical \& Electronic Engineering \\ Shandong Agricultural University \\ Shandong provincial Key Laboratory of Horticultural \\ Machineries and Equipments \\ Tai'an, China \\ Corresponding author: mtlyab@163.com
}

\begin{abstract}
PV grid connected power generation is the trend at present in the world and the grid-connected inverter is core part of PV power generation system, so high quality and low cost of inverter power supply become the focus of research. According to the characteristics of average household power, a type of photovoltaic generation system that is designed based on STC meet the need of power uses and a new type of control strategy of maximum power point tracking is suggested and make a prototype. The results show that the system can control simply, work stably, track the maximum power point faster and greatly improve the output power.
\end{abstract}

Keywords-Photovoltaic;STC;grid-connected;Inverter;MPPT

\section{INTRODUCTION}

With the aggravation of energy crisis, human beings are more anxious for renewable energy sources. At the same time, solar energy, as one kind of ideal clean energy, has been paid more and more attention to. In solar energy conversion process, inverter plays a role of intermediate link between solar array and AC distribution system. Some of its factors, such as security, reliability, inversion efficiency, fabricating cost, play an important part in the overall economic benefit of whole photovoltaic generation system. At present, photovoltaic inverter (pv) is mostly independently used, supplying local load use. STC MCU is used as CCBB in inverter in this article. Its function, the realtime generation of inverter sine waveform and tracking the voltage frequency and phase of power grid, makes it possible that it can generate electricity independently, and can also combined to the grid. This technology makes it possible that we can increase reliability and low cost of the whole system..

\section{MAIN CIRCUIT TOPOLOGY AND THE OPERATING PRINCIPLE OF MAIN CIRCUIT TOPOLOGY}

The grid-connected inverter is getting more attention as the interface device between SOPW and power grid. What are mostly used in grid with SOPW are two stage structures, that is, forward stage (DC-DC) and backward stage (DCAC).Main task of forward stage is the maximum power point tracking (MPPT) and stabilizing process of inverting $\mathrm{DC}$ voltage. At the same time, backward stage (DC-AC) is to realize process of inverting and connecting to grid.

The characteristics of household photovoltaic grid- connected inverter in this article are dual mode boost, two stages without insolation. Its circuit topology is shown in the figure 1 . We choose solar panels with its input voltage range between $120 \sim 350 \mathrm{~V}$. The forward stage realizes boosting and stabilizing voltage to $400 \mathrm{~V}$ and traces the MPP. The backward stage, full-bridge inverter circuit, inverts this voltage to AC and connects to grid via a LC filter.

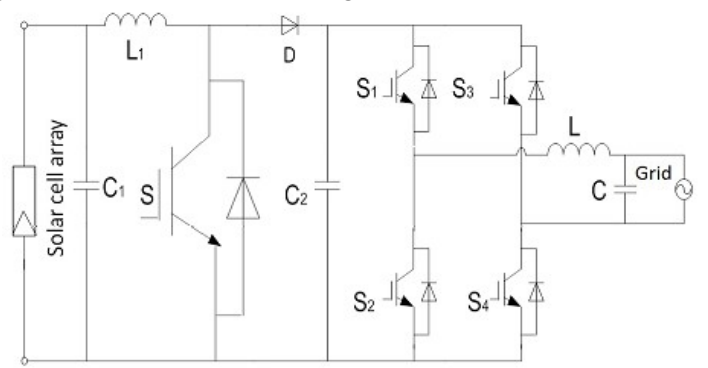

Fig.1 Topology of single-phase grid-connected inverter

\section{III.SYSTEM IMPLEMENTATION}

\section{A. Realization of MPPT}

Relation between voltage and current in solar cell is not linear, relevant working curve differs when atmospheric conditions, sunshine amount and temperature change. Each working curve has a different MPPT, called best operating point of this solar cell.

To increase the efficiency of solar power system and fully take full use of this solar cell, we need it work at the best operating point all the time, which is so called maximum power point tracking( MPPT). Virtually, process of MPPT is an optimizing process, that is, controlling output of maximum power by controlling relevant its terminal voltage. Commonly used methods are admittance differential method, CTV, disturbance observation method. Disturbance observation method, also called hill climbing method, is to trace the direction of MPPT by constantly disturbing photovoltaic system operating working point. Specific way of this method is to constantly increase or decrease the output voltage of photovoltaic system (PV system) and compare this power output with former one 
without disturbing. After that we can get the output point under maximum power. Advantages of this control method are in a simple thought, easy to realize, high efficiency in tracing, and efficiency improvement in solar power. However, it does have some disadvantages. It may give some erroneous judgment under highly changing system.

We made some improvements for this erroneous judgment by using advanced disturbance observation method to realize the MPPT. Flow chart is shown in figure 2.

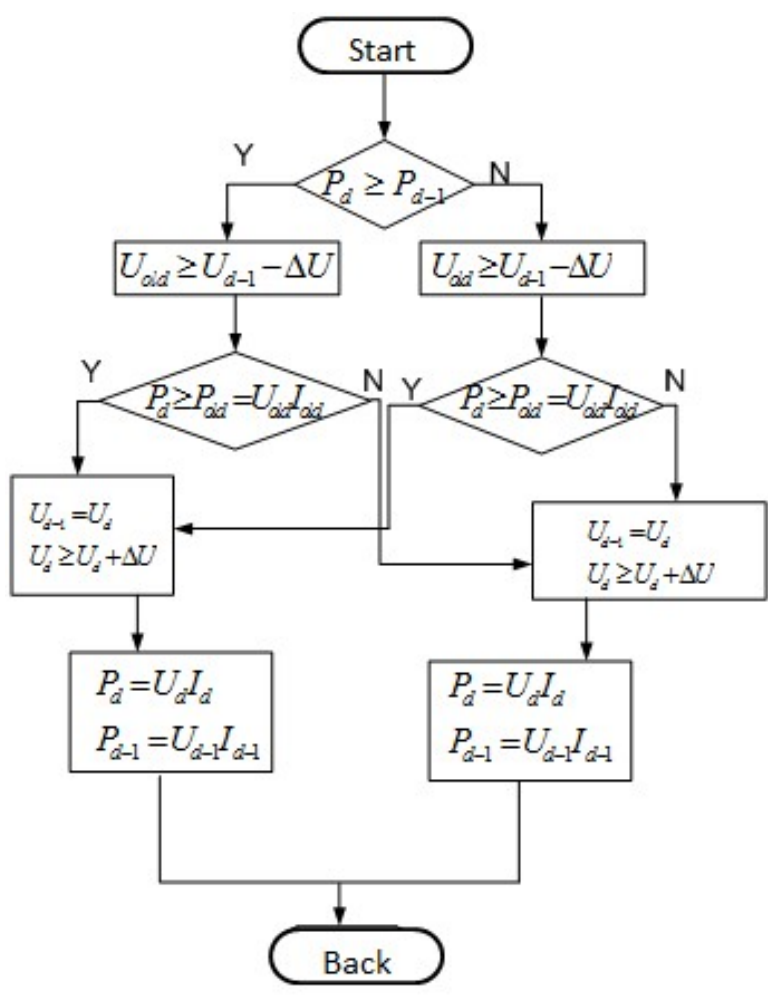

Fig.2 Flow chart of the improved P\&Q

\section{B. Design of household inverter}

Household photovoltaic (PV) grid generation system is changing DC from solar cell to AC with same frequency in power grid. The system can supply electricity to local areas and can also get electricity from the whole system. The design of whole inverter is in figure 3.

Main inverting circuit can invert DC from solar cell to AC, which has the same frequency with local power grid. STC is used as cybernetics core in the photovoltaic grid. It collects analogy value and variation trend from main circuit and provides driver board of power device with proper sinusoidal pulse width modulation (SPWM).Phase lock technique and grid current control are achieved by software. Then high-quality current will successfully connect to grid. When it is a sunny day with enough sunshine, we can turn on switch 2 and turn off switch 1 . At this time, photovoltaic system can supply enough electricity to load. When it comes to cloudy weather, switch 1 will be turned on and switch 2 will be turned off. Load can get electricity from power grid. We can guarantee reliability of power supply when the power grid fails.

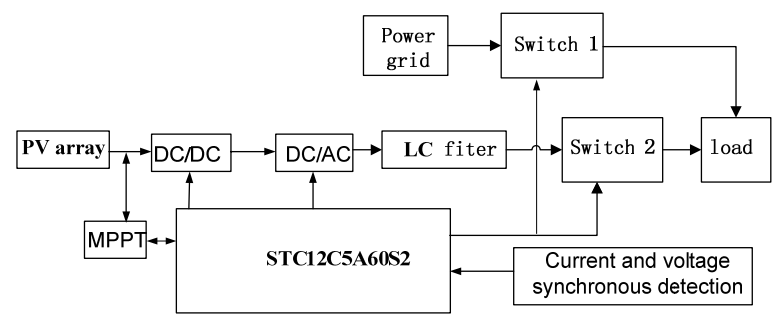

Fig.3 Block diagram of grid -inverter

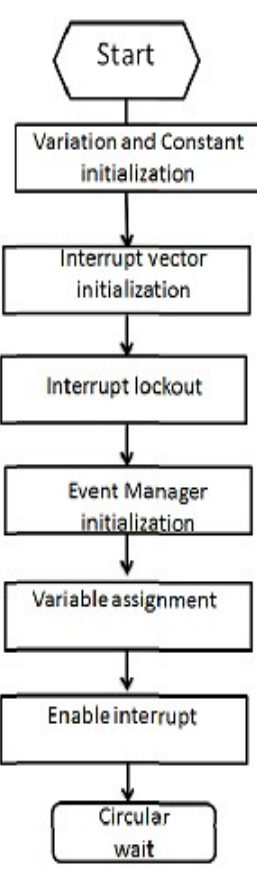

(a)

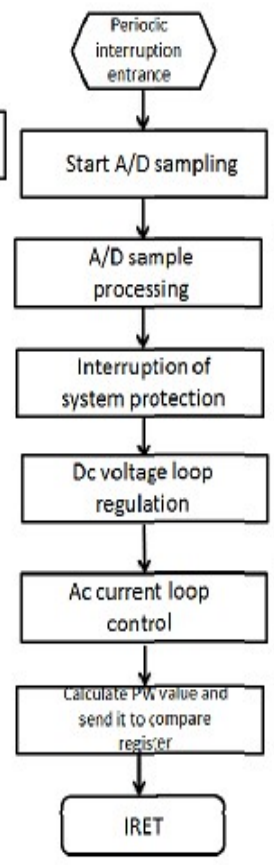

(b)

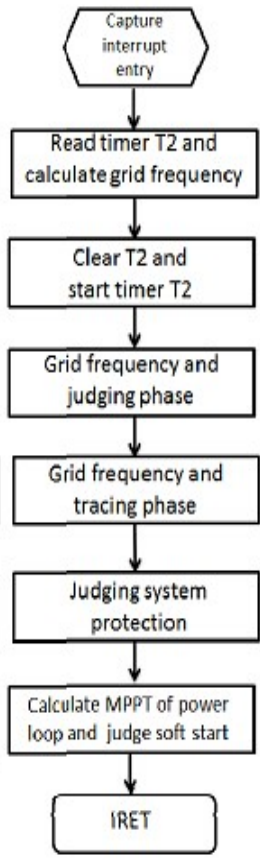

(c)
Fig.4 Program flow diagram of the system control

Control part of the system consists of several parts, which will be shown in figure 4. (a) is its main program. The function of (a) is initializing variables and circular wait. (b) is period interrupting program. Its function is creating SPWM, regulating voltage and current, and software protection. (c) is capture interrupt program. It is used to unify phase and frequency between grid-input current and power grid current and trace MPPT of photovoltaic cell array. 


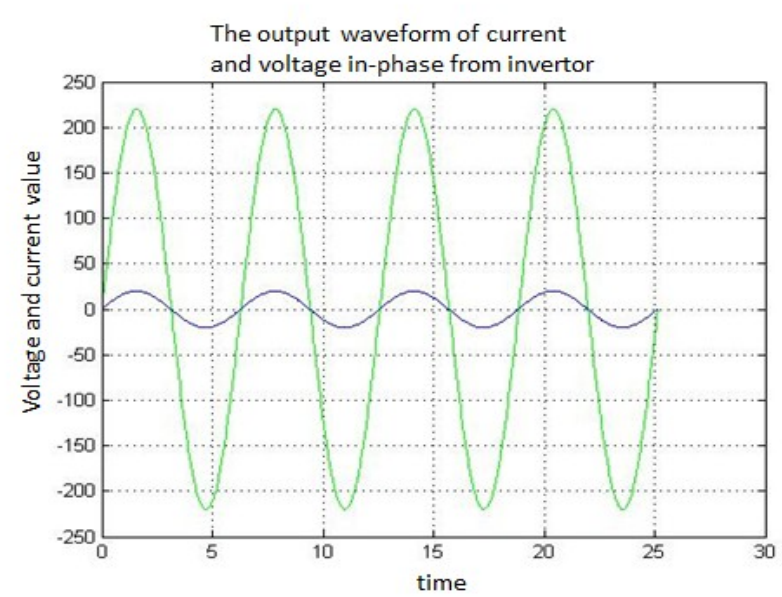

Fig.5 Waveforms of grid-connected current and grid voltage

TABLE I EXPERIMENTAL RESULTS OF THD

\begin{tabular}{|ccrrrr|}
\hline Load rate/\% & 10 & 20 & 50 & 80 & 90 \\
& 100 & & & \\
Distortion/\% & 4 & 4 & 4.3 & 4.5 & 4.5 \\
& 4.8 & & & \\
\hline
\end{tabular}

\section{EXPERIMENTS OF GRID-CONNECTED INVERTER}

Based on the design above, we choose STC as host controller. IGBT is CM100DY-12H made by Mitsubishi. The household single-phase photovoltaic grid-connected inverter is made in lab its rated power is $5 \mathrm{~kW}$. Then we did some experiments with this inverter in connecting grid. The experimental power range is $0.46 \sim 5 \mathrm{~kW}$. The input voltage range is $120 \sim 350 \mathrm{~V}$. What is shown in fig.5 is waves of output current and voltage, with its power factor about to 1 . We get distortion test results with different loads by CA8335 power quality analyzer. Results are shown in chart.1. Experimental data show that inverter's transfer efficiency can be up to $87 \%$ when harmonic content is less than $5 \%$ in output wave of inverter.

\section{V.CONCLUSION}

We successfully design household grid-connected inverter by using STC as core controller, realizing good dynamic response in this system. We also make full use of power energy by improving arithmetic in MPPT, making whole solar cell array work at MPPT. Experiments prove that this system work steadily and supply proper references to grid connection. It does have great marketing value. In the future, household photovoltaic grid-connected inverter will play an important role in smart grid.

\section{ACKNOWLEDGMENT}

This work is supported by Foundation of Shandong Education Department (J12LN01).

\section{REFERENCES}

[1] WU Yu-rong, ZHANG Guo-qin. Design of single phase photovoltaic grid-connected inverse system based on DSP [J].RELAY.2008,36 (4) :51-53

[2] LI Dong-hui, WANG He-xiong, et al. Research on several critical problems of photovoltaic grid-connected generation system [J]. Power System Protection and Control. 2010,38 (21) :208-214.

[3] ZHOU Nian-cheng, YAN Li-wei, et al. Research on dynamic characteristic and integration of photovoltaic generation in micro grids [J]. Power System Protection and Control.2010,38 (14) : 119-127.

[4] ZHANG Chang- hua. Design and MPPT Control of Home Photovoltaic Generation System [J]. Journal of Hubei University for Nationalities (Natural Science Edition)..2011,29 (2) : 194-196.

[5] HE Wei-wei, YANG Jin-ming. Research on Photovoltaic Maximum Power Point Tracking System [J]. Power System Protection and Control. 2008,42 (8) :30-32

[6] Q. Zeng, L. Chang, P. Song. SVPWM-based Current Controller with Grid Harmonic Compensation for Three-phase Grid-connected VSI. 2004-35th Annual IEEE Power Electronics Specialists Conference: 2494-2500.

[7] ZHAO Wei, YU Shi-jie, SHEN Yu-liang, et al. The control way in the grid-connected PV system based on the DSP [J]. Relay, 2002, 30(7): 31-33.

[8] Jung Youngseok, So Junghun, Yu Gwonjong. Improved perturbation and observation method (P\&Q) of MPPT control for photovoltaic power systems [C].

//Photovoltaic Specialists Conference. 2005.

[9] Bi yingRen. RESEARCH ON THE CONTROL STRATEGIES FOR THE RESIDENTIAL PHOTOVOLTAIC GRID CONNECTED GENERATION SYSTEM [D]. Xi'an University of Technology.2009.

[10] CAO Du-feng, DOU Wei, et al. Study of $30 \mathrm{~kW}$ Photovoltaic

[11] Grid-connected Inverter. [J]. Power System Protection and Control. 2009,43 (10): :42-44. 